\title{
Effect of Microclimate on Avifaunal Diversity in Brgy.Tablon, Cagayan de Oro City, Misamis Oriental, Philippines
}

\author{
Jennyveive P. Cabigquez, Leia Andion N. Corrales*, Angelica O. Millama \& Richel E. Relox
}

Department of Environmental Science and Technology, College of Science and Mathematics, University of Science and Technology of Southern Philippines, Cagayan de Oro City

Corresponding author, e-mail: chelox_8224@yahoo.com

\begin{abstract}
Avifaunal species provide a range of ecosystem services, however their habitats have been altered rapidly by anthropogenic activities. The study was conducted in the Barangay of Tablon, Cagayan de Oro City to assess the variation of bird species composition, abundance, richness and diversity with varied levels of disturbance such as agricultural, forested and residential area and correlated to the microclimate of the area. Based on the results, a total number of eight (8) avifaunal species and 377 individuals belonging to eight (8) families were identified, namely: Nectarinia jugularis, Lonchura atricapilla, Columba livia, Gallus gallus, Passer Montanus, Rhipidura superciliaris, Motacilla flava, and Hirundo rustica. The residential area has the most abundant species, while forested area has the least abundance. The forested area is more diverse among the other habitat area with a value of $H=1.172$. In terms of microclimate, if the temperature is low the number of avifauna species is lesser compared to high temperature. Meanwhile, relative humidity and precipitation have a negative correlation with species diversity. Hence, the micro-climate of the area affects the diversity of avifauna in Barangay Tablon, Cagayan de Oro City. The study serves as a baseline data that can be used for conservation and protection for the remaining forest ecosystem in Cagayan de Oro City.
\end{abstract}

KEY WORDS Avifauna; Cagayan de Oro City; habitat; protection.

Received 20.09.2020; accepted 09.04.2021; published online 28.05.2021

\section{INTRODUCTION}

Rapid population growth and urbanization, conversion of natural habitats into residential and agricultural has been rampant which has resulted to alteration of animal habitats specially avifauna (Vallejo et al., 2008). Overexploitation and forest destruction has also threatened the diversity of birds (Roy et al., 2012). The application of pesticides and herbicides to agricultural land can have negative effect to birds, as it can be toxic for avifauna and may reduce food resources to various species (Ibanez et al., 2007). Climate change also alters the distribution of avifauna because of the loss of suitable habitat (Haribon Foundation, 2014).

Philippines is a very diverse tropical country which can support various types of species. Avifauna is one of the most important ecological indicators to evaluate the quality of habitat. It provides ecosystem services to humans through their interactions with the environment. Forests are important habitat for birds because it provides food, shelter, nest site and protection as well as in agricultural 
areas. Birds play a useful role in the control of insects and pests in agricultural crops, as predators of rodents, as scavengers, as seed dispensers and as pollinating agents (Simeone et al., 2002; Manjunath, 2014).

The preservation of global species diversity has emerged as one of the most important issues today (Medona et al., 2015). In order to protect the diversity of species, Philippines have been implementing various conservation management practices with the help of local government, non-local government agencies, and the concern citizens of the Philippines. The implementation of National Integrated Protected Areas System (NIPAS) Act and the designation of important bird areas in country protect birds and all associated flora and fauna from the threat of extinction (Haribon Foundation, 2014).

In Mindanao, Cagayan de Oro City is considered to be one of the developing cities in the Philippines. Birds provide economic benefit in many cases but we often overlook their ecological significance which may be one of the reasons why the population of birds decline. Hence, this study aimed to assess the diversity of avifauna that varies among different habitats with varied levels of disturbance and specifically assesses the variation of bird species composition, abundance, richness and diversity affected by the micro-climatic and habitat factors.

\section{MATERIAL AND METHODS}

\section{Research Setting}

The study was conducted in three different habitat types within the Barangay of Tablon, Cagayan de Oro City (Fig. 1).

The sampling area is composed of three subareas: agricultural, forested and residential area.

The agricultural area was located from $\mathrm{N}$
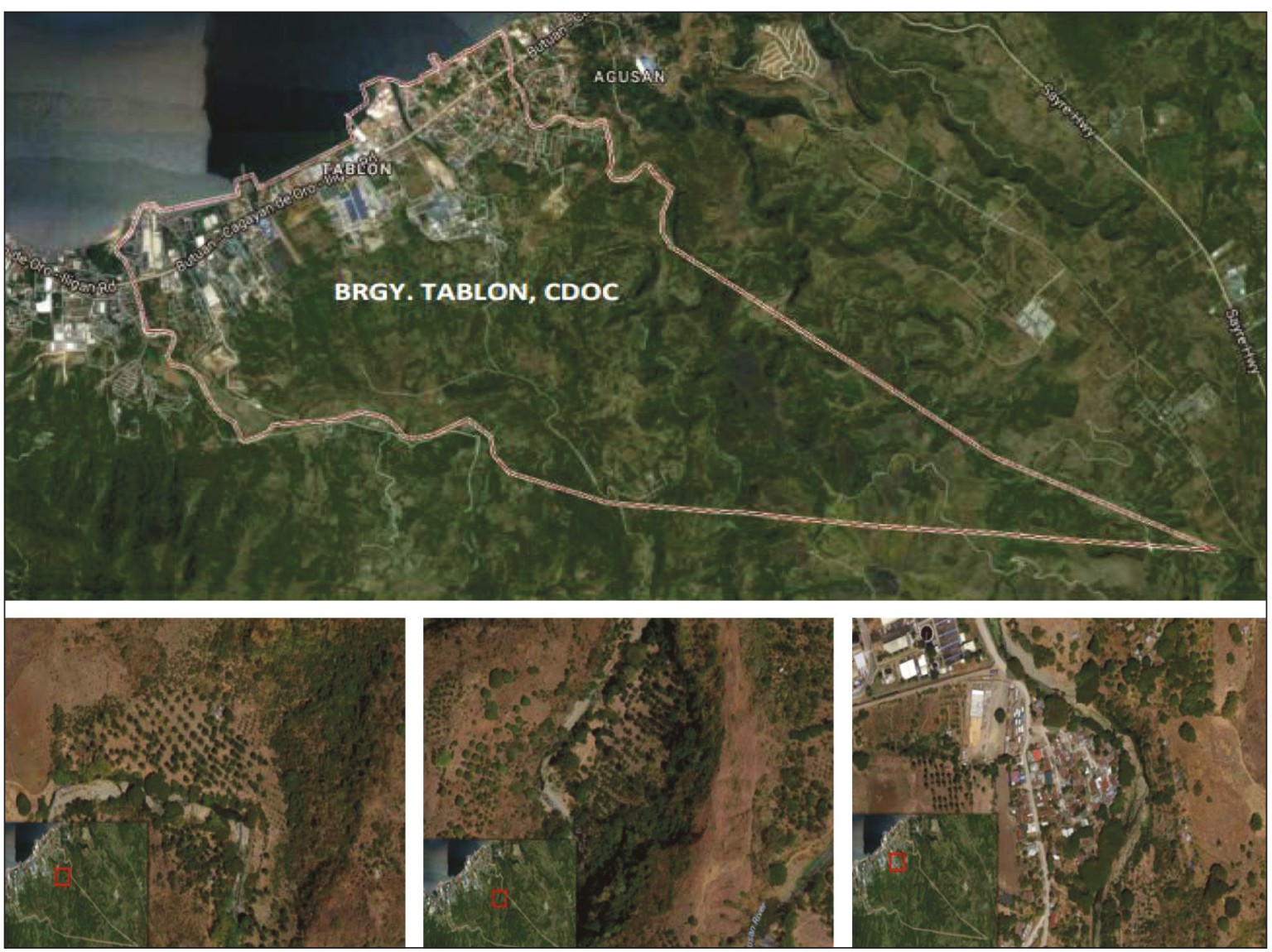

Figure 1. Satellite images of the sampling sites in Tablon, Cagayan de Oro City. 
8.47132 E, 124.73353 to N 8.47401, E 124.7334. This area is planted with coconut, banana, mango, guava, corn and many others. There are also domestic animals such as carabaos, goats, horses and chickens. Only few numbers of households were observed.

The forested area was located from N 8.47077, E 124.73949 to $\mathrm{N} 8.47314$, E 124.7376 . It is a riparian forest wherein the tree vegetation was along the sides of Umalag River. Various types of vegetation were observed but not fruit bearing ones. Other people from other places go there to log and hunt animals.

The residential area was located from $\mathrm{N}$ 8.47593 , E 124.73315 to N 8.47703, E 124.73132. There are numerous households present in the area and they domesticate chicken and carabao.

\section{Bird Sampling and Analysis}

Line transect and mist-netting methods were used to study moving species such as birds. Ten mist nets were established per habitat type until no new species are added into the list from September to November 2016 (Cailing et al., 2018, Relox et al., 2011; Quitain et al., 2016). Species captured were measured and identified according to the species level by the use of references such as Guide to the Birds of the Philippines and with the help of Department of Environmental and Natural Resources (DENR) Region X. Line transect method was also used to record species that were present around the area but were not caught by the mist netting method. A one kilometer distance was also measured through each habitat type. Observation, identification and ocular inspection was also noted during the duration of sampling.

\section{Micro-Climate Data Collection}

The climate of each habitat type during sampling was collected from the area using anemometer and PAG-ASA (Philippine Atmospheric, Geophysical and Astronomical Services Administration) including rainfall, temperature and relative humidity of each habitat. Micro-climatic factors such as ambient temperature, rainfall, and relative humidity were correlated to the avifaunal diversity in each habitat type.

\section{RESULTS}

\section{Bird Species Diversity}

There are eight species that belongs to eight Families and four Orders categorized into six Passeriformes, one Columbiformes, and one Galliformes of bird observed from the sampling sites of Tablon, Cagayan de Oro (Table 1).

In the agricultural area, a total number of 126 specimens were found where Red Junglefowl ( $\mathrm{Gal}$ lus gallus) is the most abundant species with a total of $63.49 \%$ of the total relative abundance of all species found. In the forested area, only 21 specimens were found, where Chestnut Munia (Lonchura atricapilla) is the most abundant species with a total of $47.62 \%$ of the total species in the area. In the residential area, a total of 230 specimens were found, where Tree Sparrow (Passer montanus) is the most abundant species with a total of $51.30 \%$ of the total percent of all species (Table 2).

\section{Micro-Climatic Factors Affecting Avifaunal Species}

The agricultural area has the second lowest temperature $\left(28.2{ }^{\circ} \mathrm{C}\right)$ and lowest relative humidity $(68.85 \%)$. During sampling period, the weather was dry and rainfall $(7 \mathrm{~mm})$ occurs often. On the other hand, the forested area has the lowest temperature $\left(27.75^{\circ} \mathrm{C}\right)$ and high relative humidity $(72.08 \%)$. In the residential area, it shows that the highest temperature $\left(31.58^{\circ} \mathrm{C}\right)$ and $69.32 \%$ of relative humidity recorded (Fig. 2).

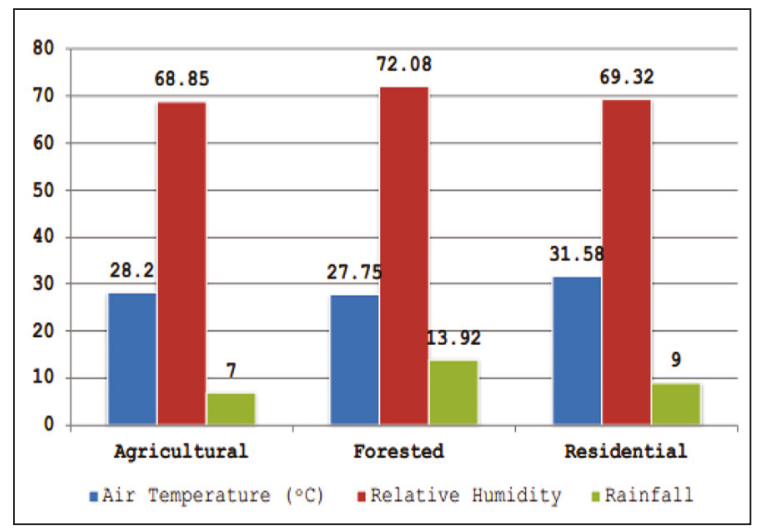

Figure 2. Micro-climatic factors in three habitat types in Tablon, Cagayan de Oro City. 


\begin{tabular}{|c|c|c|c|c|}
\hline FAMILY & SCIENTIFIC NAME & AGRICULTURAL & FORESTED & RESIDENTIAL \\
\hline Hirundinidae & Hirundo rustica & $/$ & $\mathrm{x}$ & $\mathrm{x}$ \\
\hline Phasianidae & Gallus gallus & $/$ & $\mathrm{x}$ & $/$ \\
\hline Columbidae & Columba livia & $/$ & $/$ & $\mathrm{x}$ \\
\hline Rhipiduridae & Rhipidura superciliaris & $\mathrm{x}$ & $/$ & $\mathrm{x}$ \\
\hline Motacillidae & Motacilla flava & $\mathrm{x}$ & $/$ & $/$ \\
\hline Estrildidae & Lonchura atricapilla & $\mathrm{x}$ & $\mathrm{x}$ & $/$ \\
\hline Passeridae & Passer montanus & $/$ & $\mathrm{x}$ & $\mathbf{5}$ \\
\hline Nectariniidae & Nectarinia jugularis & $\mathrm{x}$ & $\mathbf{4}$ & $\mathbf{5}$ \\
\hline
\end{tabular}

Table 1. Bird species in three habitat types in Barangay Tablon, Cagayan de Oro City.

\begin{tabular}{|c|c|c|c|c|c|c|}
\hline \multirow{2}{*}{ SPECIES } & \multicolumn{2}{|c|}{ AGRICULTURAL } & \multicolumn{2}{c|}{ FORESTED } & \multicolumn{2}{c|}{ RESIDENTIAL } \\
\hline & $\mathrm{n}$ & $\mathrm{RA}$ & $\mathrm{n}$ & $\mathrm{RA}$ & $\mathrm{n}$ & $\mathrm{RA}$ \\
\hline Hirundo rustica & 6 & 4.76 & 0 & 0 & 0 & 0 \\
\hline Gallus gallus & 80 & 63.5 & 0 & 0 & 80 & 37.8 \\
\hline Columba livia & 18 & 14.3 & 1 & 4.8 & 20 & 8.7 \\
\hline Rhipidura superciliaris & 0 & 0 & 4 & 19.1 & 0 & 0 \\
\hline Motacilla flava & 0 & 0 & 6 & 28.6 & 0 & 0 \\
\hline Lonchura atricapilla & 0 & 0 & 10 & 47.6 & 2 & 0.9 \\
\hline Passer montanus & 22 & 17.5 & 0 & 0 & 118 & 51.3 \\
\hline Nectarinia jugularis & 0 & 0 & 0 & 0 & 10 & 4.4 \\
\hline TOTAL & 126 & 100 & 21 & 100 & 230 & 100 \\
\hline
\end{tabular}

Table 2. Relative abundance (RA) of birds in habitat types of Tablon, Cagayan de Oro City.

\begin{tabular}{|l|l|l|l|l|}
\hline \multirow{2}{*}{ SPECIES } & \multicolumn{4}{|c|}{ MICROCLIMATIC FACTORS } \\
\cline { 2 - 5 } & Air Temperature & Relative Humidity & Rainfall & \\
\hline Avian Diversity & 0.063 & -0.091 & -0.96 & Pearson Correlation \\
\cline { 2 - 5 } & 0.96 & 0.27 & 0.18 & P-value \\
\hline
\end{tabular}

Table 3. Correlation of birds diversity and micro-climate in in Tablon, Cagayan de Oro City.

\section{DISCUSSIONS}

The results obtained from this study shows that the diversity and evenness $(\mathrm{H}=1.172, \mathrm{E}=0.8454)$ in the forest area is much higher compared to the other sampling sites. Among the species, Gallus gallus is abundant in the agricultural area because of the presence of their food and domesticated by 
the residents. On the other hand, Lonchura atricapilla prefers swampy habitats such as swampy grassland, since the forested area is a riparian forest.

Tree sparrow is abundant in the area since the residential is somewhat a rural area because there are only few homes. This may imply that the other areas, particularly the agricultural and residential areas, do not have the greater number of species because of dominant species. Forms of habitat disturbance, such as cutting of trees due to urbanization, hunting, as well as loss of resources, lead to the destruction of the avifauna species.

The microclimatic conditions of the agricultural area can be explained by the presence of the crops planted in the area which serves as shades in the area. On the other hand, the forested area climate is attributed to its proximity to the stream and surrounded with a lot of vegetation. Rainfall usually occurs which has the highest average amount of rainfall $(13.92 \mathrm{~mm})$ during sampling period which might be a reason why least number of species is found in the area. During sampling period, the weather was always dry and rainfall $(9 \mathrm{~mm})$ occurs sometimes but species are most abundant in the residential area because species tend to stay in the shades of the house or trees and in the ceiling of the house.

Since avifauna diversity is greatly affected by air temperature, it resulted to a positive correlation (Table 3). If the temperature is low the number of avifauna species is lesser compared to high temperature. Relative humidity and precipitation have a negative correlation with species diversity. Vegetation alters the microclimate which blocks the wind and shading various. Areas that are vegetated can cool the surroundings with higher tree and shrub resulting in cooler air temperature (Chang et al., 2007).

\section{CONCLUSIONS}

Thus, the residential area has the most abundant species but is has low diversity, since dominant species are present. Avifaunal species is abundant in the area since fruit bearing trees are present as well as feeds of livestocks. Micro-climatic factors such as air temperature, relative humidity and rainfall are recorded highest in the residential area and lowest in forested area. Avifaunal species are diverse in the forested area since the temperature is favorable for them to reproduce with the presence of stream that may regulate high temperature.

\section{REFERENCES}

Cailing C., Caban J., Cultura R. \& Relox R.E., 2018. Relationship of Avifauna and Mangroves in Laguindingan, Misamis Oriental, Philippines. Journal of Biodiversity and Environmental Sciences, 13: 216222.

Chang C., Li M. \& Chang S., 2007. A preliminary study on the local cool-island intensity of Taipei city parks. Landscape and Urban Planning, 80: 386-95.

Haribon Foundation, 2014. The State of the Philippine Birds. Haribon Foundation for the Conservation of Natural Resources Inc., Quezon City.

Ibanez C., Curco A., Riera X., Ripoll I. \& Sanchez C., 2007. Influence of Rice Field Management Practices on Birds in the Growing Season.

Kennedy R., Gonzales P., Dickinson E., Miranda H. \& Fisher T., 2000. A Guide to the Birds of the Philippines. Oxford University Press, 347 pp.

Manjunath \& Joshi BN., 2014. Avifauna of Chandrampalli, Chincholi, Gulbarga District Karnataka. International Journal of Research in Applied, Natural and Social Sciences, 2: 1-10.

Medona M., Nirmala R. \& Dephine Rose M., 2015. Feeding Guild And Diversity of Avifauna At Sothuparai Reservoir, Periyakulam, Theni District, Tamilnadu, India.

Relox R., Leaño E. \& Camino F., 2011. Avifaunal assemblage in Mt. Hamiguitan, Davao Oriental, Mindanao Island, Philippines. Journal Environmental Science and Management, 14: 1-11.

Quitain D., Dejadena N., Medina M., Relox R. \& Leaño E., 2016. Birds of Mainit hot spring protected landscape, Nabunturan, Compostela valley, Province Mindanao island, Philippines. Journal of Biodiversity and Environmental Science, 9: 149155.

Roy U., Banerjee P. \& Mukhopadhyay S., 2012. Study on avifaunal diversity from three different regions of North Bengal, India. Asian Journal of Conservation Biology, 1: 120-129.

Simeone A., Araya M., Bernal M., Diebold E., Grzybowski K., Michaels M., Teare J., Wallace R. \& Willis M., 2002. Oceanographic and climatic factors influencing breeding and colony attendance patterns of Humboldt Penguins in central Chile. Marine Ecology Progress Series, 227: 43-50. 
Vallejo B., Aloya A., Ong P., Tamino A. \& Villasper J., 2008. Spatial Patterns of Bird Diversity and Abun- dance in an Urban Tropical Landscape: The University of the Philippines Diliman Campus. 